\title{
Foucault y la resistencia. Una gramática del concepto
}

\section{Foucault and the Resistance. A Grammar of the Concept}

\author{
RODRIGO CASTRO ORELLANA \\ Universidad Complutense de Madrid
}

Recibido: 10/11/2015 Aceptado:30/12/2015

\begin{abstract}
RESUMEN
El artículo estudia la irrupción del concepto de resistencia en la filosofía de Foucault, atendiendo a sus diversas formulaciones en el contexto del desarrollo de la analítica del poder. Dentro de este marco general, se establecen dos hipótesis fundamentales: que el concepto de resistencia es una reactivación del problema del afuera formulado en los escritos sobre literatura y en los trabajos arqueológicos; y que la noción se ve interpelada una y otra vez por una definición tautológica que no logra separarla del concepto de poder. De esta forma, asumiendo el carácter defectivo del concepto de resistencia, se concluye con una evaluación de sus limitaciones y posibilidades a partir de un diálogo con algunos de sus principales críticos.
\end{abstract}

PALABRAS CLAVE

RESISTENCIA, PODER, AFUERA, LIBERTAD, GUBERNAMENTALIDAD

\begin{abstract}
The article examines the emergence of the concept of resistance in Foucault's philosophy, according to their various formulations in the context of the development of analytical power. Within this general framework, they set two fundamental assumptions: that the concept of resistance is a problem of "outside" reactivation formulated in both writings on literature and the archaeological work; and that the notion is challenged again and again by a tautological definition that fails to separate the concept of power. In this way, assuming the defective nature
\end{abstract}

(C) Contrastes. Revista Internacional de Filosofía, vol. XXII-Nº1 (2017), pp. 45-63. ISSN: 1136-4076

Departamento de Filosofía, Universidad de Málaga, Facultad de Filosofía y Letras Campus de Teatinos, E-29071 Málaga (España) 
of the concept of resistance, concludes with an assessment of their limitations and possibilities from a dialogue with some of its main critics.

KEYWORDS

RESISTANCE, POWER, OUTSIDE, FREEDOM, GOVERNMENTALITY

FOUCAULT FUE UN CREADOR DE CONCEPTOS. Sin embargo, la recepción de su pensamiento no se ha detenido a reflexionar suficientemente respecto a la naturaleza de dicho taller inventivo. Ha existido una cierta desatención de lo que involucra el proceso experimental de reelaboración constante de nociones que pone en práctica el filósofo francés. Esa permanente transformación de su producción teórica ha sido leída como un itinerario de rupturas y contradicciones o como una incapacidad para ofrecer criterios normativos y universales. No se ha sabido ver en ella una opción sustantiva, una forma de entender la labor del pensamiento, y lo que quizás sea más interesante, un modo de definir lo que es un concepto.

En tal sentido, quiero defender en este trabajo la hipótesis de que el pensamiento de Foucault opera con la idea de una «imposible omnideterminación teórica» de los conceptos políticos. Esto sería lo que está en juego de manera decisiva, cuando señala, por ejemplo, que su investigación es una analítica del poder y no una teoría del mismo; una advertencia que quizás nunca ha sido efectivamente tomada en serio por muchos comentaristas.

Mi intención en este texto consiste en establecer la defectividad del concepto foucaultiano de resistencia. Esto quiere decir que dicho concepto tendría que ser situado en una doble historicidad: aquella que corresponde a los contextos de producción, circulación y usos (ecología del concepto) y aquella que se refiere a la contingencia interna de su irrupción y de sus derivas (gramática del concepto). ${ }^{1}$ En ambos casos, el concepto es objeto de una constante reelaboración que acredita tanto la ausencia de una totalidad o plenitud lógica como la necesidad vital de su eficacia. De esta manera, el concepto foucaultiano de resistencia se inscribe en un régimen discursivo precario de transformación constante, dentro del cual se persigue la reactivación sucesiva del mismo. A continuación presentaré un relato esquemático de esta historia interna del concepto de resistencia, es decir: su gramática dentro de la filosofía de Foucault.

\section{ANTECEDENTES DEL CONCEPTO}

Mi segunda hipótesis es la siguiente: el concepto de resistencia que aparece en los textos de Foucault de los años setenta, constituye una reactivación del

1 J. Lezra, Materialismo salvaje. La ética del terror y la república moderna. Madrid: Biblioteca Nueva, 2012, p. 182. 
problema de la experiencia del afuera formulado en los escritos sobre literatura y en los trabajos arqueológicos de los años sesenta. Para explicar esto último resulta preciso recordar el juego de lo Mismo y lo Otro que se expone en la descripción arqueológica de las ciencias humanas, respecto a los procesos que han constituido la modernidad y su pensamiento sobre el hombre, y que implican una distinción entre un lenguaje primero, de carácter discursivo, y un lenguaje segundo que expresaría el «ser del lenguaje» en la literatura. El estudio de las diferentes mutaciones epistémicas en Les Mots et les Choses identifica de un modo recurrente la singularidad de una «experiencia-otra» que escapa al orden propio del sistema, una alteridad que surgiría en la conducción del lenguaje a sus confines.

No es casual, por tanto, que se encuentren en la literatura los ejemplos privilegiados que ilustran la tensión de un límite. Así ocurre con El Quijote de Cervantes en relación al Renacimiento ${ }^{2}$, con Sade a propósito de la época Clásica $^{3}$, y con Nietzsche, Bataille o Artaud ${ }^{4}$ respecto a la modernidad. En cada uno de estos casos, la experiencia literaria aparece investida de un doble gesto de ruptura y apertura, y la labor de la escritura se muestra como una tarea decisiva en la que se bosqueja un compromiso con la transformación de la realidad.

Sin embargo, hay un peligro que subyace en el intento de reflexionar sobre esta experiencia del afuera, pese a todo su poder transgresor. Al respecto nos advierte Foucault cuando señala la posible reconducción de la experiencia literaria a la idea de interioridad. Frente a esto propone la conversión del lenguaje reflexivo en un pensamiento que se dirige a su extremo, no para encontrar en el borde la positividad que lo contradice, sino para hallar el vacío, ir hacia él, y borrarse en el silencio de un «afuera en que las palabras se extienden indefinidamente». ${ }^{5}$ Dicho de otra forma, se plantea una huída de toda interiorización, una toma de distancia respecto a la función expresiva de la subjetividad, una escapatoria que la literatura sugiere y hace evidente en sus relieves cuando remite al ser bruto del lenguaje y convierte al «hablo» en una voz vacía.

Según Judith Revel, el «pensamiento del afuera» aparece como una fuerza que erosiona el orden del discurso, como una especie de reabsorción de todas las posibilidades de la diferencia en la transgresión de la dialéctica razón/sinrazón. ${ }^{6}$ El afuera contendría una esperanza de liberación en la

$2 C f$. M. Foucault. Les mots et les choses. Paris: Éditions Gallimard, 1966, p. 60 ss

$3 C f$. Michel Foucault. Les mots et les choses. Op. cit., p. 222 ss

4 Cf. Michel Foucault. Les mots et les choses. Op. cit., p. 316-317, 339, 394-396

5 Michel Foucault. «La pensée du dehors», en: Dits et écrits I. Paris: Éditions Gallimard, 1994, No 38, p. 523.

6 J. Revel. Foucault, un pensamiento de lo discontinuo. Buenos Aires: Amorrortu, 2014, 
cual un individuo singular consigue, especialmente a través de la escritura, interpelar a los dispositivos de identificación, clasificación y normalización del discurso ${ }^{7}$. Habría algo que desborda, excede, fractura la continuidad del pensamiento y su potencia de formalización de lo real.

No obstante, Foucault va a descubrir muy pronto los problemas de esta perspectiva. La discontinuidad que introduce la experiencia literaria se encontraría excesivamente apegada al «caso radical» e impide articular una transgresión más allá de la singularidad extraordinaria o la soledad individual. No existe recomposición que sea posible desde el gesto del «hombre infame», ni tampoco hay cabida para un espacio de articulación o intersubjetividad más allá de la dimensión puntual de la dispersión. Además, la cuestión del afuera parece ser cada vez más una ilusión que sitúa la potencia de la creatividad en el margen o un engaño que define la alteridad como lo monstruoso o lo completamente extraño al orden. La locura o la delincuencia-llegará a decir Foucault- no nos hablan desde una exterioridad absoluta, sino desde el interior de las redes de poder que conforman una sociedad. ${ }^{8}$

En este contexto, resulta interesante comparar el estudio de la transgresión literaria con el trabajo sobre la situación carcelaria que Foucault efectuó dentro del GIP (Groupe d'information sur les prisons) a principios de la década del setenta. ${ }^{9}$ Se podría suponer que, en ambos casos, se trata de dar cuenta sólo del caso individual situado en los márgenes. Pero los cuestionarios utilizados por el GIP y que se aplican a los presos, no arrojan como resultado demandas individuales de reforma de las condiciones de la vida carcelaria, sino un complejo proceso de re-subjetivación que pretende alcanzar una dimensión colectiva y que denuncia un poder opresivo que se oculta en la justicia, la técnica o el saber. ${ }^{10}$ La pregunta, entonces, sería: ¿en qué consiste esta dimensión subjetiva que reacciona frente al poder y que interpela una racionalidad dominante y la praxis que la acompaña? ¿Cómo entender esta fuerza reactiva si prescindimos del mito de la exterioridad y, por tanto, la inscribimos en el interior de las relaciones de poder? En definitivas cuentas, ¿qué es resistir sin un afuera?

Pienso que todo el desarrollo de la analítica del poder es una consecuencia de esta irrupción del problema de la resistencia y una reactivación de la cuestión

p. 108 .

7 Ibid., p. 112.

8 Michel Foucault. «L'extension sociale de la norme», en: Dits et écrits III, Paris: Éditions Gallimard, $\mathrm{N}^{\mathrm{o}} 173$, p. 77.

9 Cf. Benedikte Zitouni: «Michel Foucault et le Groupe d'information sur les prisons: Comment faire exister et circuler le savoir des prisonniers», en: Les Temps Modernes, 2007/4 (No 645-646): 268-307.

10 Judith Revel. Foucault, un pensamiento de lo discontinuo. Op. cit., p. 136. 
del afuera que se expresa ahora en términos de una radical desmitificación. En tal sentido, los dos conceptos (poder-resistencia) se hallan articulados y se superponen desde su génesis. La pregunta por el poder siempre va a implicar la pregunta por la resistencia. Si el poder es productivo, la resistencia es inventiva; si el poder se desplaza, la resistencia es móvil; si uno viene de abajo, la otra también se distribuye microfísicamente, etcétera. Es decir, la construcción inicial de ambas categorías ya estaría atravesada por la tautología en una medida tal que todos los desplazamientos posteriores de la analítica poder/resistencia pueden ser interpretados como un esfuerzo por superar esta relación de identidad. Aún más, podríamos decir que el verdadero interés teórico que subyace en los diagnósticos foucaultianos sobre los dispositivos de poder, tiene que ver con lograr establecer el sentido en que la resistencia podría contener una diferencia.

\section{Poder y ESTRATEGIA}

Quisiera, en este punto, recordar algunos aspectos generales de las primeras formulaciones que Foucault realizó de la analítica del poder. Como sabemos, para el pensador francés el poder es, antes que nada, una «situación». ${ }^{11}$ No es algo que se posee, consiste más bien en la articulación de un espacio o una escena. Dicho con más precisión, nadie detenta de manera particular el poder, dado que éste no constituye una propiedad de la cual se pueda disponer. Por el contrario, es una función que se ejerce y se desplaza de manera activa por el territorio de lo social.

De tal modo, el Estado, por ejemplo, no se podría entender como un foco que monopoliza el poder; sino que habría que comprenderlo como un «efecto de conjunto o una resultante de una multiplicidad de engranajes y de núcleos que se sitúan en un nivel completamente distinto, y que constituyen de por sí una microfísica del poder». ${ }^{12}$ Aún más, reducir el problema del poder al problema del Estado constituiría un obstáculo metodológico para dar cuenta del control político del cuerpo social. ${ }^{13}$ Solamente descartando la idea de un «Gran Poder» y asumiendo el carácter plural de las relaciones de poder, parece posible avanzar en la lectura de los mecanismos más intrincados de sometimiento que se ponen en práctica en las sociedades modernas.

Por otra parte, la «situación» que el poder representa posee un carácter «estratégico», lo cual se traduce en que las relaciones de poder han de ser

11 Michel Foucault. Histoire de la sexualité 1: La volonté de savoir. Paris: Éditions Gallimard, 1976, p. 123.

12 Gilles Deleuze. Foucault. Barcelona: Paidós, 1987, p. 51.

13 Julián Sauquillo. Michel Foucault: Una filosofía de la acción. Madrid: Centro de Estudios Constitucionales, 1989, p. 299. 
pensadas como relaciones de fuerza que se ejercen sobre los cuerpos y de acuerdo a ciertos fines tácticos. Por eso, el término «estrategia» debe ser acogido en toda su acepción bélica. Dicho sentido sería el que mejor dibuja los desplazamientos, las tensiones y las variaciones que se dan en el espacio abierto de las relaciones de poder. La «situación estratégica» sería un campo de batalla en que el poder se desliza de acuerdo a una lógica que no es prioritariamente represiva, sino de carácter productivo.

En la clase del 7 de enero de 1976 del curso del Collège de France Il faut défendre la société, Foucault plantea que una vez que nos hemos liberado de los esquemas economicistas, persisten dos posibilidades de lectura del poder: la hipótesis Reich que establece como mecanismo del poder a la represión y la hipótesis Nietzsche que enfatiza el enfrentamiento belicoso de fuerzas como el fondo último de la relación de poder. ${ }^{14}$ Estas dos hipótesis no se excluyen mutuamente sino que pueden configurar un sistema de análisis del poder político que en definitivas cuentas se contrapone al esquema del derecho, la soberanía y el contrato. La pregunta por lo legítimo y lo ilegítimo, se sustituye por el problema de la lucha y la sumisión.

Sin embargo, en este mismo curso del año 1976, Foucault señala que el modelo histórico-político sustentado por los conceptos de represión y lucha, todavía está «insuficientemente elaborado» y que incluso dichas nociones deberían llegar a modificarse o tal vez a abandonarse. ${ }^{15}$ En el caso de la idea de represión, la crítica tendrá un desarrollo bastante radical y explicito en la investigación foucaultiana posterior, alcanzando su máxima intensidad con el estudio del dispositivo de la sexualidad. No ocurre lo mismo en el caso de la interpretación de las relaciones de poder desde la metáfora de la guerra. $\mathrm{Al}$ respecto, la perspectiva de Foucault es mucho más compleja y en algunas oportunidades ambivalente.

En este contexto, resulta ilustrativo detenerse un momento en la lectura que Foucault realiza del Estado hobbesiano como supuesta conquista de la civilidad y finalización de la guerra. Según el autor francés, el status naturalis descrito por Hobbes no se correspondería realmente con una lucha fratricida, brutal y directa; sino más bien con una «indiferenciación natural», en donde lo que existe es un estado de incertidumbre en el cual proliferan representaciones acerca del otro, manifestaciones, expresiones, voluntades que se disfrazan, inquietudes, etcétera. ${ }^{16}$ Es decir, se trataría de un «teatro de

14 Michel Foucault. Il faut défendre la société. Cours au Collège de France. 1976. Paris: Gallimard/Seuil, p. 17

15 Ibid., p. 18

16 Ibid., p. 79. 
las representaciones intercambiadas» ${ }^{17}$ atravesado por el temor y la voluntad de vivir. En Hobbes realmente no habría guerra en el punto de partida, sino las infinitas escaramuzas que nacen del simple hecho de que ella pueda llegar a ser posible.

La soberanía, entonces, solamente se podría constituir a partir de las representaciones de individuos atemorizados y no desde sujetos sumidos en una guerra interminable que puede conducir a la aniquilación mutua o a la victoria del más fuerte. De esta segunda figura, parece que únicamente podrían surgir amos y esclavos, aunque -como señala Foucault- la escena de la dominación puede representar para Hobbes un momento de la soberanía. En la opción que hacen los vencidos a favor de la vida y la obediencia, por ejemplo, Hobbes entiende que está comprometida una elección implícita que éstos realizan a favor de los vencedores como sus representantes. ${ }^{18}$

Es decir, todo sucede como si la guerra fuese una amenaza exterior, una posibilidad que justifica el momento soberano, algo siempre retrasado e instalado en lo virtual. De esta forma, se niega la existencia de una guerra primitiva y permanente que circula en medio y por debajo de ese aparato de Estado que supuestamente suspendería toda lucha. Para Foucault, operando de esta manera, Hobbes persigue bloquear el historicismo político, esto es: «la necesidad lógica e histórica de la rebelión». ${ }^{19}$ El triunfo del Leviathan ocultaría, entonces, las relaciones de fuerza y los gestos de resistencia que determinan la totalidad del espacio político.

Ahora bien, la importancia de esta lectura foucaultiana de Hobbes reside en que la reivindicación del modelo de la guerra como grilla de análisis del poder frente al modelo jurídico, supone una incompatibilidad radical entre ambos. Las relaciones de poder involucrarían una batalla que nunca se interrumpe para dar lugar a un «orden exento de dominación». ${ }^{20}$ De hecho, la resistencia consistiría aquí en una activación permanente de la guerra frente a cualquier discurso o práctica que pretenda introducir la ficción de la paz o la simulación de una tregua. El sujeto que resiste no reclamaría derechos ni reconocimientos jurídicos, se instalaría en la pura materialidad corporal del enfrentamiento porque la vida, en un sentido nietzscheano, no sería otra cosa que un combate perpetuo.

Como podrá observarse, esta deriva de su analítica del poder conduce a

17 Idem.

18 Michel Foucault. Il faut défendre la société. Cours au Collège de France. 1976. Op. cit., p. 82.

19 Ibid., p. 96.

20 Pablo López Álvarez. «La guerra infinita, el enigma de la sublevación. Michel Foucault y la interpretación bélica de la política», en: Nicolás Sánchez Durá (Ed.). La guerra.Valencia: Pre-Textos, 2006, p. 172. 
Foucault a una descripción de la existencia política como un estar expuesto permanentemente a la dominación, una vivencia física del sufrimiento que arrastra consigo la batalla interminable y una experiencia de la resistencia como extrema disponibilidad para la muerte. Pero: ¿cómo compatibilizar este resultado teórico con las expresiones más significativas de la militancia política de los años setenta que Foucault conoció de cerca y que compartió? ¿Cómo compaginar esta expresión estrictamente corporal de la resistencia con un discurso de denuncia del poder en nombre de ciertos derechos?

En 1971, los primeros manifiestos y folletos del GIP, consideraban al Estado como una realidad intolerable y defendían el trabajo de las encuestas no como una forma de mejorar o «hacer más soportable un poder opresivo a los presos», sino como un ataque destinado simplemente a intensificar una lucha colectiva. ${ }^{21}$ En cambio, pocos años después, a propósito del célebre proceso contra Klaus Croissant, Foucault se posicionó claramente en defensa del derecho del acusado a disponer de un abogado, alegando que dicho derecho «no constituye una abstracción jurídica, ni un ideal soñador, este derecho forma parte de nuestra realidad histórica y no debe desaparecer». ${ }^{22}$

El Estado, entonces, deja de ser considerado como una instancia que solamente merece nuestro rechazo más radical y ahora pasa a ser reconocido como un interlocutor histórico en nuestras demandas de justicia. ¿Cómo explicar este desplazamiento a partir de los supuestos iniciales de la analítica del poder? ¿Se trata de un episodio de aquello que Veyne denominó la balcanización de los cerebros $^{23}$ ? ¿Estamos frente al caso de una perfecta disociación entre el exceso teórico -que a cierto nivel parece permitirse el intelectual- y aquello que el contexto social impone como una exigencia? Ciertamente, como señala Moreno Pestaña: «en función de los contextos ejercitamos creencias diferentes y lógicamente incompatibles». ${ }^{24}$ No obstante, no creo que el problema se resuelva con la mera identificación de la estructura sociológica compleja y contradictoria en que se inscribe un sujeto. En mi opinión, el asunto exige una exploración de la contingencia interna que afecta a toda tarea de producción de un planteamiento conceptual.

21 Michel Foucault. «Préface», en: Dits et écrits II. Paris: Éditions Gallimard, 1994, N 91, p. 195.

22 Michel Foucault. «Va-t-on extrader Klaus Croissant?», en: Dits et écrits III. Paris, Éditions Gallimard, 1994, No 210, p. 365. Croissant alcanzó notoriedad en Alemania como abogado de la Fracción del Ejército Rojo (RAF), también conocida como el grupo terrorista Baader-Meinhof. En septiembre de 1977 fue detenido en Francia y se inició un polémico proceso que culminó con su extradición a Alemania y su condena a dos años y medio de cárcel.

23 Paul Veyne. Les Grecs ont-ils cru à leurs mythes. París: Seuil, 1983, p. 122-123.

24 José Luis Moreno Pestaña. «El poder psiquiátrico y la sociología de la enfermedad mental: un balance», en: Revista de Sociología Histórica, No 6, 2015. 
En tal sentido, como hemos subrayado, los conceptos de poder y resistencia están sujetos a un permanente ejercicio de reelaboración. En su desarrollo ofrecen una y otra vez enormes tensiones a la hora de satisfacer la finalidad que persigue el trabajo analítico de Foucault: expandir el espacio de lo político e intensificar la necesidad y las posibilidades de la rebelión. Desde esta perspectiva, la propia actividad militante del filósofo francés, en sus diversas articulaciones (compromiso con estudiantes detenidos, solidaridad con los inmigrantes, denuncia de regimenes dictatoriales, etcétera), se puede comprender como una experiencia teórico-práctica de superación de la idea del poder como mero combate físico de fuerzas, y como el espacio formativo del concepto de gobierno.

Foucault constata que la conquista y defensa de derechos puede operar como una forma de fractura y de determinación de los límites del ejercicio del poder. ${ }^{25}$ En la lógica de la resistencia, por tanto, subyace la potencia de conquistar derechos. Habría una dimensión belicosa que hace posible la vindicación, institucionalización y defensa de los mismos, y que no se corresponde con la pura expresión corporal de una fuerza. ${ }^{26}$ Esto no supone un retorno a la centralidad de la soberanía o una reafirmación del modelo de la guerra ni tampoco una restauración de algún tipo de fundamento trascendental. Por el contrario, aquí el asunto principal está en reconocer que los derechos tienen menos que ver con una apelación al hombre en sí, que con un enfrentamiento que libran los sujetos contra las condiciones de circulación del poder. ${ }^{27}$ Dichas condiciones son las acciones de individuos e instituciones que pretenden producir comportamientos, es decir, que intentan asegurar y reforzar espacios de gobierno y administración de la vida.

\section{PODER Y LIBERTAD}

En los cursos de 1977 a 1979 del Collège de France (Sécurité, territoire, population y Naissance de la biopolitique), se materializa la transición desde un modelo bélico del poder, que se asumió como provisorio, al modelo del gobierno. Este último supondría el despliegue de una dinámica organicista que apunta a la acción de los individuos y donde resulta imprescindible una subjetividad que responda en relación con un otro y en relación consigo misma. A partir de este momento, en la investigación foucaultiana, adquirirá relevancia la noción de gubernamentalidad como el conjunto constituido por instituciones, procedimientos, reflexiones y tácticas que tienen como meta una

25 Pablo López Álvarez. «La guerra infinita, el enigma de la sublevación. Michel Foucault y la interpretación bélica de la política». Op. cit., p. 178.

26 Ibid.., p. 181.

27 Ibid.., p. 182. 
regulación de la población; es decir, el desarrollo de una biopolítica. Aquí no debemos olvidar que estos mecanismos de gestión de una totalidad viviente no anulan -según Foucault- las tecnologías individualizantes características de los micropoderes disciplinarios.

En cualquier caso, ya sea desde la perspectiva del dispositivo global o desde el punto de vista microfísico, las relaciones de poder tendrán ahora que ser concebidas como una transformación de la acción libre de individuos o grupos $^{28}$ y no como una anulación o supresión de toda conducta. Si el modelo de la guerra permitía entender la resistencia como un elemento interno al juego político y no como una exterioridad, el nuevo modelo del gobierno ofrece una elaboración más compleja de aquello que supone ese espacio sin un afuera. Por resistencia cabría entender la elección posible que condiciona el contenido táctico de una tecnología de poder y también la reacción inesperada que determina su fracaso 29 .

Es decir, la relación de poder sería una acción que opera sobre las acciones, eventuales o actuales, de los individuos. ${ }^{30}$ Esto implica que la relación de poder, para ser tal, exige el reconocimiento del otro como sujeto de acción y, al mismo tiempo, que ante esta relación se abra un campo de respuestas, efectos y posibles invenciones. La afirmación de Foucault es rotunda: «El poder no se ejerce más que sobre "sujetos libres" y en tanto que son "libres"». ${ }^{31}$ Por esta razón, ni la figura de la violencia ni la del consenso, permiten definir el modo de ejercicio del poder, puesto que éste se despliega siempre sobre un campo de posibilidades. La relación con el otro, en este contexto, no consiste en la destrucción, ni en una oposición entre elementos, ni tampoco en el encuentro y la reconciliación de las partes dentro de una supuesta comunidad discursiva. Ante el otro, opera más bien la provocación, la incitación o la seducción.

Dicho de otro modo, las relaciones de poder son formas de «conducción de conductas» que necesitan, para funcionar, de la virtualidad del comportamiento $\mathrm{y}$, por ende, no anulan aquello sobre lo que actúan. En la violencia y en el consenso, por el contrario, se suspende este intento de determinación de la conducta del otro, el juego estratégico queda cerrado por la fuerza ciega que cercena toda posibilidad o permanece suspendido por la tregua del acuerdo. Esto no quiere decir que la violencia y el consenso no puedan ser instrumentos

28 Judith Revel. Foucault, un pensamiento de lo discontinuo. Op. cit., p. 199.

29 El uso del concepto de resistencia no desaparece después de La voluntad de saber (1976) con la irrupción de la noción de gubernamentalidad. Por ejemplo, en el decisivo texto de 1983 «El sujeto y el poder», el concepto de resistencia aparece mencionado en varias oportunidades en un contexto donde el poder se estudia como gobierno.

30 Michel Foucault. «Le sujet et le pouvoir», en: Dits et écrits IV. Paris: Éditions Gallimard, 1994, No 306, p. 237.

31 Idem. 
de las relaciones de poder. Lo que ocurriría es que la lógica de la sujeción opera bajo un principio muy distinto. Foucault identifica claramente dicho principio cuando afirma que, en el juego estratégico la libertad aparece como condición de existencia del poder, es decir, «[...] es necesario que haya libertad para que el poder se ejerza $[\ldots] \gg .{ }^{32} \mathrm{Si}$ el poder sólo se ejerce sobre aquél que aún tiene cierta posibilidad de elección, debemos concluir que la libertad es un principio operativo del poder.

Esta afirmación radical de la libertad abre en el seno de las determinaciones históricas, sociales y políticas las condiciones para una experiencia de la resistencia como una práctica que prescinde de la ilusión del afuera y del sueño de un retorno a un estado natural sin servidumbre. La realidad de lo político queda estructurada como un orden estrictamente inmanente saturado de relaciones de fuerza, enfrentamientos siempre reversibles, una lucha perpetua y multiforme en donde las relaciones de poder suscitan necesariamente un modo de contestación. ${ }^{33}$ Habría un «agonismo» entre relaciones de poder e intransitividad de la libertad ${ }^{34}$, que tiene como telón de fondo la multiplicación de los procedimientos de gobierno de los individuos o las poblaciones y su constante derrocamiento.

Sin embargo, en todo este análisis, subsiste un problema muy importante. La relación recíproca que enlaza poder y libertad pareciera estar condenada irremediablemente a no superar la tautología, toda vez que la resistencia tiene una respuesta especular frente a los mecanismos de coerción. Tacticismo, flexibilidad, inmediatez o transversalidad son en realidad características comunes a un poder que en último término se presenta como contra-resistencia y a una resistencia que sería en definitivas cuentas un contra-poder. Foucault fue perfectamente consciente de este dilema. Por eso, pueden interpretarse las diferentes elaboraciones de la analítica del poder como un intento de superación de la tautología a través de la búsqueda de un argumento que permita establecer una disimetría esencial entre poder y libertad. ${ }^{35}$ Pero, ¿en qué correspondería fundar esta posible naturaleza asimétrica de los juegos del poder y la resistencia?

En una entrevista de 1978, Foucault parece inclinado a romper la circularidad del argumento estableciendo un privilegio cronológico y ontológico de la resistencia: «El poder -afirma- nace de una pluralidad de relaciones que se injertan en otra cosa, nacen de otra cosa y hacen posible otra

32 Michel Foucault. «Le sujet et le pouvoir». Op. cit., p. 238.

33 Michel Foucault. «Pouvoir et savoir», en: Dits et écrits III. Op. cit., No 216, p. 407.

34 Michel Foucault. «Le sujet et le pouvoir». Op. cit., p. 239.

35 Judith Revel. Foucault, un pensamiento de lo discontinuo. Op. cit., p. 204. 
cosa». ${ }^{36}$ Esta idea de una enigmática realidad que precede al poder, sugiere un camino que finalmente no será recorrido por la investigación foucaultiana. Describir semejante alteridad del poder, implicaría superar la estructura tautológica poder-resistencia cediendo al argumento de una instancia originaria que funcionaría como condición de posibilidad de la otra. Foucault descarta asignar «al poder una función ontológicamente segunda respecto de un origen ontológicamente libre». ${ }^{37}$

El camino que en cambio sí desarrollará Foucault para preservar su hipótesis de la implicación recíproca del poder y la libertad e introducir una diferencia entre ambos términos, consistirá en identificar dos modos distintos de producción. Sabemos que las relaciones de poder están en un proceso permanente de expansión productiva y transformación de estrategias, en cuyo centro se encuentra el desarrollo de formas de gobierno que pretenden modelar la subjetividad. Pero también la resistencia es productiva, en tanto en cuanto genera nuevas formas de subjetividad que responden a los dispositivos de poder obligándolos a una reactivación constante. Esto significa que tanto el poder como la resistencia son reaccionarios, se nutren el uno del otro, se modifican a partir de las limitaciones que les ofrece su adversario.

Según Revel, una lógica sería esencialmente gestionaria de lo existente y la otra estaría orientada a la creación de formas de ser nuevas. ${ }^{38}$ Las relaciones de poder cumplirían una función administrativa de la subjetividad (contención, canalización, explotación, organización, etcétera), mientras que las relaciones de resistencia supondrían una invención de lo que todavía no es, es decir, la creación de nuevas experiencias a partir de la transgresión de los límites que históricamente nos son asignados. Sin lugar a dudas, esto último explicaría y dotaría de sentido, el período final de la investigación foucaultiana; la cuestión del cuidado de sí, el problema de la parrhesia, el estudio del bios philosophicos cínico, etcétera. Todo este capítulo del pensamiento de Foucault se podría entender como una continuación de la analítica del poder en los términos de una historia de las prácticas de resistencia. ${ }^{39}$

\section{LIMITACIONES}

Quisiera concluir señalando tres limitaciones que podrían observarse en la última elaboración que Foucault nos ofrece del concepto de resistencia. Si, como hemos sugerido, la analítica del poder presenta diversas y contrapuestas

36 Michel Foucault. «Précisions sur le pouvoir. Réponses à certaines critiques», en: Dits et écrits III. Op. cit., № 238, p. 631.

37 Judith Revel. Foucault, un pensamiento de lo discontinuo. Op. cit., p. 206.

38 Ibid.., p. 209.

39 Ibid.., p. 211. 
aproximaciones al significado que podría tener esta noción, evaluar las eventuales limitaciones de su formulación final supondría reflexionar sobre el sentido de una nueva reactivación del concepto. No se trata aquí, entonces, de desplegar una inútil defensa filológica de la obra de un autor frente a sus críticos, sino del problema -por lo demás tan característico del proceder foucaultiano- del uso y la efectividad de un discurso teórico.

IV.1. Primera observación crítica. Se trataría del problema de la articulación entre las distintas formas de resistencia que se presentan en una sociedad. ¿Qué es aquello que hace posible la intersección entre diversos tipos de lucha para que se produzca un movimiento de contestación generalizado? ¿No es necesario que exista algo más que la fuerza de un rechazo compartido para que converjan diversos modos de resistencia en una demanda global? ¿No corresponde dibujar y distinguir tipos de resistencia colectiva en función de intereses, ideologías o valores contrapuestos? Es decir, desde este punto de vista se precisaría de principios articuladores externos al espacio contingente de las relaciones de poder para que irrumpa una movilización popular en que una heterogeneidad de modos de resistencia puedan inscribirse en una lógica común y transversal.

La proliferación de las resistencias no podría permanecer en el puro nivel de la producción de diferencias. Tendría que existir algún elemento trascendente y universal que garantice la irrupción de identidades políticas que permitan prácticas emancipadoras. Como bien sabemos, las ideas de libertad y justicia han cumplido ese papel de encadenamiento de las luchas particulares, pero también intereses aún menos definidos como, por ejemplo, el deseo de orden social han operado como criterios de articulación, agrupamiento y generalización de las demandas específicas de los sujetos.

No obstante, habría que observar que para Foucault no existe una relación entre la negación del afuera y la negación de la posibilidad de articulación entre formas de resistencia. Por una parte, estaría la necesidad de entender todo ideal, valor o ideología como una construcción histórica que se produce en el interior de un campo de fuerzas inmanente. Por otro lado, correspondería identificar la articulación de los modos de lucha con objetivos tácticos que solamente pueden ser inteligibles dentro del espacio de las relaciones de poder. Así, por ejemplo, puede afirmarse -como lo hace Foucault en «Le sujet et le pouvoir»- que las luchas se cruzan y se ligan en atención a su inmediatez, su cuestionamiento del status del individuo, su oposición a los regímenes de saber, su intento de romper con la política de «doble vínculo» (individualización y totalización), etcétera. ${ }^{40}$

40 Michel Foucault. «Le sujet et le pouvoir». Op. cit., pp. 226-232. 


\section{Como señala en La volonté de savoir:}

Nos enfrentamos a puntos de resistencia móviles y transitorios, que introducen en una sociedad líneas divisorias que se desplazan rompiendo unidades y suscitando reagrupamientos, abriendo surcos en el interior de los propios individuos, cortándolos en trozos y remodelándolos, trazando en ellos, en su cuerpo y su alma, regiones irreducibles. Así como la red de relaciones de poder concluye por construir un espeso tejido que atraviesa los aparatos y las instituciones sin localizarse exactamente en ellos, así también la formación del enjambre de los puntos de resistencia surca las estratificaciones sociales y las unidades individuales. Y es sin duda la codificación estratégica de esos puntos de resistencia lo que forma posible una revolución. ${ }^{41}$

IV.2. Si la historicidad del poder guarda relación con la necesidad permanente de modificar los dispositivos y reinventar las tácticas que responden a la potencia creativa de los nuevos espacios que genera la resistencia, ¿no significa esto que las propias formas de lucha contribuyen a un proceso por medio del cual la dominación se hace cada vez más eficaz y peligrosa? Dicho de otro modo: la capacidad de la resistencia para modular las relaciones de poder no garantizaría ninguna emancipación real, sino simplemente una intensificación y complejización de los mecanismos de sometimiento. El poder incrementaría su densidad y vigor en la misma medida en que la tarea de la resistencia consistiría en responder al desafío creciente y agotador de crear nuevas modalidades de contestación.

Esta crítica, por tanto, incide nuevamente en la necesidad de un elemento exterior a este campo de fuerzas cerrado en el que poder y resistencia parecen cada vez más similares. Sin embargo, tomando en consideración la crítica foucaultiana al universalismo y la necesidad de una articulación de la multiplicidad de las resistencias; se vislumbra aquí la posibilidad de pensar ese elemento exterior como un universal vacio que permita establecer una nueva legitimidad de las luchas y un nuevo concepto sobre su fuerza articuladora y su capacidad efectiva de oposición frente a las potencias coercitivas. Evidentemente, en este contexto, cabría inscribir la tesis hegemónica de Laclau y Mouffe.

En Hegemonía y Estrategia Socialista se encuentra el siguiente pasaje:

Aunque podemos afirmar con Foucault que donde quiera que haya poder hay resistencia, también se debe reconocer que las formas de resistencia pueden ser extremadamente variadas. Solo en ciertos casos toman estas resistencias un

41 Michel Foucault. Histoire de la sexualité 1: La volonté de savoir. Op. cit., p. 127. 
carácter político y se convierten en luchas dirigidas a terminar con las relaciones de subordinación como tales. ${ }^{42}$

Desde este punto de vista, el infinito antagonismo de las estrategias formulado por Foucault, podría ser interpretado como una expresión radical de la contingencia y del deslizamiento de «significantes flotantes» sin articulación. ${ }^{43}$ Hasta aquí no habría política, es decir -en los términos de Laclau- no se efectuaría la construcción de una identidad popular. El momento político o la irrupción del «pueblo» realmente comenzaría cuando emerge la disputa y el conflicto en pos de inscribir a las luchas en un orden equivalencial. En esta coyuntura, según el pensador argentino, no sirve el universalismo ciego ante la contingencia ni tampoco la pura celebración del particularismo sin un referente que tenga fuerza articuladora.

Esto último aleja a Laclau de los esencialismos de la tradición marxista y del nihilismo postmoderno. Se requeriría, según su punto de vista, de un elemento universal externo a las relaciones de poder que opere como un lugar vacío, esto es: como un referente abierto no predeterminado, siempre sujeto a redefiniciones, y que tiene la posibilidad de unir o enlazar demandas, exigencias, necesidades polimorfas que provienen del espacio pre-político y abigarrado de las resistencias. Sería necesario, por tanto, un «pensamiento del afuera» que permita introducir un corte en la totalidad social, establecer la frontera que sitúa a los actores y sus prácticas dentro del conjunto de las equivalencias o en el exterior de dicho sistema. Sin la noción de afuera la política no podría ser concebida como un espacio del antagonismo y de las identidades afectivas.

Como se comprenderá, no pretendo ofrecer en este punto un estudio comparativo de los planteamientos de Foucault y Laclau. Solamente me gustaría indicar, como respuesta a esta crítica, que no es para nada evidente que la «exterioridad vacía» consiga superar el problema de un poder que incrementa su eficacia en la medida que se le oponen nuevas modalidades de lucha. Habría que considerar si los actores que resisten políticamente lo hacen en nombre de una universalidad abierta o si un sujeto que lucha se articula con otro a partir de una plena autoconciencia de que los afectos que le movilizan dependen de un «significante vacío».

En definitivas cuentas: ¿qué ventaja política tiene que el intelectual llegue a comprender el carácter contingente y abierto de los ideales articuladores, si en el ámbito de las prácticas el hombre común vivencia estos significantes

42 Ernesto Laclau; Chantal Mouffe. Hegemonia y Estrategia Socialista. Hacia una radicalización de la democracia, Madrid: Siglo XXI, 1987, p. 171.

43 Cf. Ernesto Laclau. La razón populista. Buenos Aires: Fondo de Cultura Económica, 2005, pp. 163 ss. 
como criterios cerrados que justifican el totalitarismo o la violencia? ¿Cómo podríamos reconocer que estamos del lado del universal vacío y no del universal absoluto? Y ¿en qué medida situarse del lado del primero puede garantizar que estemos más cerca de la emancipación que de la barbarie?

Por el contrario, para Foucault, no es posible interrumpir la peligrosidad del poder y ésta no puede obedecer a una teleología histórica de la dominación creciente. Por eso el papel del filósofo no podría residir en reconducir los poderes o en proporcionar un horizonte deseado pero inalcanzable. La filosofía debería abandonar su pretensión legisladora, retórica, profética o utópica. El problema del poder no podría ser formulado en términos de bien o mal, sino que tiene que plantearse como un análisis empírico y topológico de una realidad en ejercicio. ${ }^{44}$

IV.3. Tercera y última observación crítica. Un argumento que intenta romper la afirmación radical de la inmanencia que contiene el análisis foucaultiano, esta vez por el lado del reconocimiento implícito de que la disimetría entre poderes y resistencias obedece efectivamente a una contraposición entre una lógica gestionaria y una lógica creativa. La idea sería que la potencia inventiva de la resistencia tiene que provenir necesariamente de un afuera que escape en alguna medida al espacio de las relaciones de poder. Esta es la tesis de Judith Butler, para quien existiría una especie de «psicoanálisis suprimido» en el pensamiento de Foucault, que podría identificarse cuando el francés intenta establecer el lugar de la resistencia en el contexto de los procesos de producción del sujeto. ${ }^{45}$

Los poderes, de acuerdo a la analítica foucaultiana, actúan sobre los cuerpos e incluso dentro de los cuerpos modelando una forma de relación del sujeto consigo mismo, determinando una identidad o, como se afirma en Surveiller et punir, inventando un alma. Pero, ¿cómo entender esa interioridad que aquí es nombrada por Foucault? ¿Se trata de una pura ficción que nace de la sujeción o hay allí algo así como una existencia previa a la «in-corporación» de esa alma que va a ser colonizada? ¿Sobre qué materialidad se instalan, operan y se multiplican los dispositivos de poder antes de que emerja un cuerpo disciplinado o un individuo obediente?

Para Butler el sujeto siempre «surge a costa del cuerpo y su aparición se halla inversamente condicionada por la desaparición del cuerpo». ${ }^{46} \mathrm{El}$ «yo», entonces, expresaría la forma espectral de un cuerpo avasallado y destruido

44 Michel Foucault. «La philosophie analytique de la politique», en: Dits et écrits III, $\mathrm{N}^{\mathrm{o}}$ 232. Op. cit., p. 540.

45 Judith Butler. Mecanismos psíquicos del poder. Teorías sobre la sujeción. Madrid: Cátedra, 1997, p. 99.

46 Ibid., p. 104. 
con el objetivo de dar lugar a una identidad. Esto último permite suponer la permanencia de un residuo, algo así como el retorno fantasmagórico de un cuerpo salvaje y no normalizable. La resistencia al poder tendría que ver, entonces, con este fondo inasimilable que se manifiesta como una fuga constante ante la cual el poder fracasa una y otra vez. Por eso, el sujeto foucaultiano nunca es producido instantáneamente a través del sometimiento, sino que siempre está en vías de ser producido. ${ }^{47}$

La hipótesis de Butler consiste en plantear que del mismo modo que en el psicoanálisis el sujeto no es equivalente a la psique de la cual emerge; en Foucault, el sujeto no sería equivalente al cuerpo del cual emerge. Esto supondría que el pensador francés ha investido al cuerpo de un significado psíquico que no consigue desarrollar dentro de su esquema teórico. ${ }^{48} \mathrm{El}$ cuerpo sería, por una parte, lo que desborda los sistemas de dominación; pero, por otro lado, dicha dimensión solamente podría ser conceptualizada a través de una noción de «inconsciente» que Foucault no está dispuesto a asumir por diversas razones.

Tampoco pretendo aquí desarrollar un análisis sobre la lectura que Butler hace de Foucault y los distintos episodios de la crítica al psicoanálisis que se desarrollan en la obra del pensador francés. Solo quisiera subrayar, a modo de conclusión, que el planteamiento de Butler acierta y se equivoca al mismo tiempo. Creo que está en lo correcto cuando apunta en la dirección de un capítulo ausente en las investigaciones foucaultianas. Se trataría de una teoría acerca de la materialidad de la vida que, sin embargo, y en esto yerra Butler, no puede reposar en una sustancialización del inconsciente ni en la referencia deleuzeana al deseo.

Habría que pensar la vida en una dimensión estrictamente social e histórica, en su expansión extensiva y orgánica, de un modo que nos permita comprender su enorme capacidad de articular nuevas formas y su potencia reactiva frente a la repetición de lo Mismo. En pocas palabras, estaría pendiente la exploración de aquello que quizás en el último curso del Collège de France, Foucault comenzaba a indagar con la noción de «bios». La articulación defectiva del concepto y de la vida, que nos muestra la profunda insatisfacción del ser humano ante la existencia y su inagotable voluntad de sublevarse.

\section{REFERENCIAS BIBLIOGRÁFICAS}

BUTLER, J. Sujetos del deseo. Reflexiones hegelianas en la Francia del siglo XX, Buenos Aires: Amorrortu, 2012.

, Mecanismos psíquicos del poder. Teorías sobre la sujeción, Madrid: Cátedra,

47 Ibid., p. 106.

48 Ibid., pp. 107-108. 
1997.

DELEUZE, G. Foucault, Barcelona: Paidós, 1987.

ERIBON, D. Michel Foucault y sus contemporáneos, Buenos Aires: Nueva Visión, 1995.

FOUCAULT, M. Les mots et les choses, Paris: Éditions Gallimard, 1966 (Trad. Esp. Las palabras y las cosas. México: Siglo XXI, 1995).

, «La pensée du dehors», en: Dits et écrits I, Paris: Éditions Gallimard, 1994, Nº 38

, «L'extension sociale de la norme», en: Dits et écrits III, Paris: Éditions Gallimard, $\mathrm{N}^{\circ} 173$.

, Histoire de la sexualité 1: La volonté de savoir, Paris: Éditions Gallimard, 1976.

, Il faut défendre la société. Cours au Collège de France. 1976, Paris: Gallimard/ Seuil

, «Préface», en: Dits et écrits II, Paris, Éditions Gallimard, 1994, Nº

, «Va-t-on extrader Klaus Croissant?», en: Dits et écrits III, Paris, Éditions Gallimard, 1994, Nº 210.

, «Le sujet et le pouvoir», en: Dits et écrits IV, Paris, Éditions Gallimard, 1994, $\mathrm{N}^{\mathrm{o}} 306$.

, «Pouvoir et savoir», en: Dits et écrits III, op. cit., № 216

, «Précisions sur le pouvoir. Réponses à certaines critiques», en: Dits et écrits III, op. cit., $\mathrm{N}^{\mathrm{o}} 238$.

, «La philosophie analytique de la politique», en: Dits et écrits III, Nº 232.

LACLAU, E; MOUFFE, C. Hegemonía y Estrategia Socialista. Hacia una radicalización de la democracia, Madrid: Siglo XXI, 1987.

LACLAU, E. La razón populista. Buenos Aires: Fondo de Cultura Económica, 2005.

LEZRA, J. Materialismo salvaje. La ética del terror y la república moderna, Madrid: Biblioteca Nueva, 2012.

LÓPEZ ÁLVAREZ, P. «La guerra infinita, el enigma de la sublevación. Michel Foucault y la interpretación bélica de la política», en: Nicolás Sánchez Durá (Ed.). La guerra, Valencia: Pre-Textos, 2006,

MORENO PESTAÑA, JL. «El poder psiquiátrico y la sociología de la enfermedad mental: un balance», en: Revista de Sociología Histórica, No 6, 2015.

REVEL, J. Foucault, un pensamiento de lo discontinuo, Buenos Aires: Amorrortu, 2014.

SAUQUILLO, J. Michel Foucault: Una filosofia de la acción, Madrid: Centro de Estudios Constitucionales, 1989.

ZITOUNI, B. «Michel Foucault et le Groupe d'information sur les prisons: Comment faire exister et circuler le savoir des prisonniers», en: Les Temps Modernes, 2007/4 (No 645-646): 268-307. 
Rodrigo Castro Orellana es Profesor Contratado Doctor Departamento de Historia de la Filosofía, Estética y Teoría del Conocimiento, Facultad de Filosofía, Universidad Complutense de Madrid

Líneas de Investigación:

Filosofía contemporánea, filosofía política, teorías postcoloniales y pensamiento latinoamericano

Publicaciones recientes:

CASTRO, R. y SALINAS, A. (eds.) (2016): La actualidad de Michel Foucault. Madrid: Escolar y Mayo (ISBN: 978-84-16020-67-6).

(ed.) (2015): Poshegemonía. El final de un paradigma de la filosofía política en América Latina. Madrid: Biblioteca Nueva (ISBN: 978-84-16345-12-0).

Correo electrónico: rodrigocastro@filos.ucm.es 